\title{
Tabakprävention: die neuen Themen!
}

\author{
Jacques Cornuz, Carole Clair \\ Medizinische Poliklinik des Universitätsspitals Lausanne
}

Die wirksamen Massnahmen zur Tabakprävention sind bekannt: 1) Besteuerung Tabakprodukte aufgrund der Nachfrageelastizität; 2) Verbot jeglicher direkter und indirekter Werbung zur Reduktion der Nachfrage; 3) Passivrauch-Gesetz um die Gesundheit von Nichtrauchenden zu schützen und den Tabakkonsum zu denormalisieren; 4) Rauchstoppberatung mit Verschreibung von Medikamenten gegen die Nikotinentzugssymptome [1]. In vielen Ländern, auch in der Schweiz, sind Ärztinnen und Ärzte eine Allianz mit den Gesundheitsbehörden eingegangen, um diese Massnahmen in Kraft zu setzen. Anlässlich des Welttags ohne Tabak machen wir uns Gedanken zur Tabakprävention und stützen uns dabei auf einen kürzlich erschienenen Artikel [2].

Seit einigen Jahren, mit dem Aufkommen der E-Zigarette, wird es komplizierter! Sehen Sie selbst:

1. ein Gerät - die elektronische Zigarette - das von der Zigarette nur den Namen hat, das weder Tabak noch seine tödlichen Verbrennungsprodukte (Kohlenwasserstoffe, Nitrosamine, proteolytische Enzyme) enthält, aber eine Flüssigkeit, die inhaliert wird, nachdem sie erhitzt und verdampft wurde

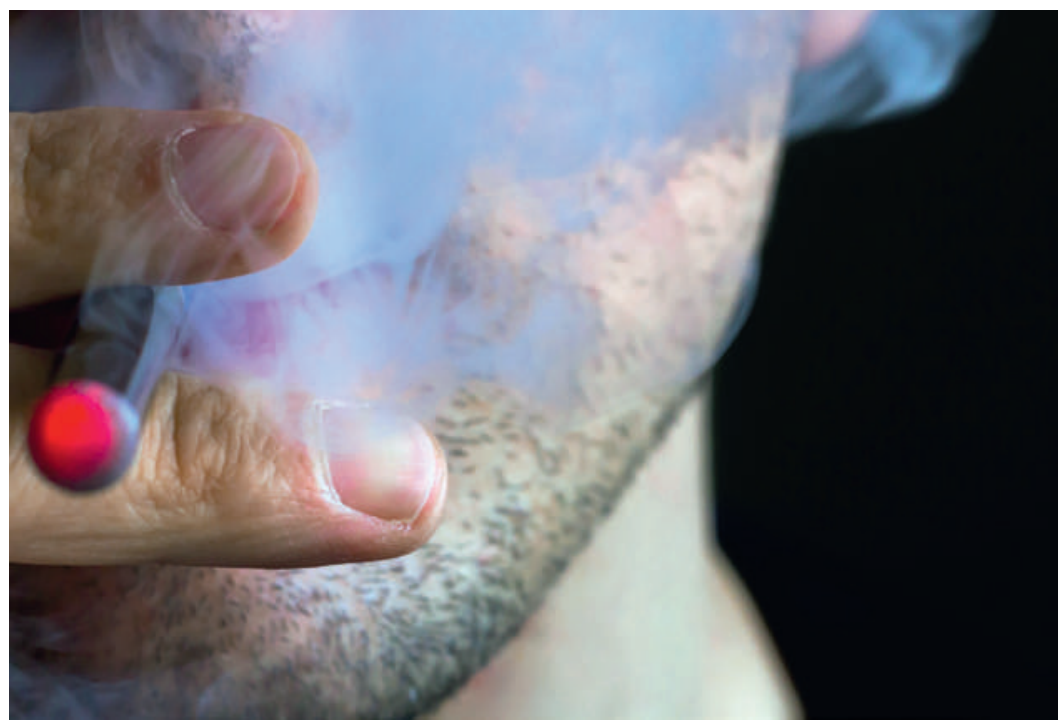

Die E-Zigarette: Soll Werbung für dieses Produkt zugelassen werden?
2. Dampf, dessen Inhalation zwar keine grösseren kurzfristigen Folgen hat, dessen langfristigen Auswirkungen aber unbekannt sind

3. eine Substanz - das Nikotin - deren süchtig machende Wirkung besonders bei Jugendlichen hoch sein könnte, deren Zentralnervensystem noch nicht ausgereift ist

\section{Die wissenschaftlichen Daten zu den Auswir-} kungen der elektronischen Zigarette sind noch sehr fragmentarisch.

4. ein Verhalten - das Dampfen - sehr individuell hinsichtlich Intensität und Häufigkeit, schwer zu standardisieren für die klinische Forschung

5. ein ganzes Gerät + Flüssigkeit + Nikotin, dessen Wirksamkeit für die Tabakentwöhnung wenig wissenschaftlich dokumentiert ist, aber dessen empirische Daten nahelegen, eine Hilfe bei der Beendigung oder Reduktion des Tabakkonsums zu sein

6. ein heterogener Regulierungsrahmen je nach Land, der vom Verbot (Schweden) bis zur Liberalisierung (Grossbritannien, Frankreich) reicht

7. ein volatiler Markt, der sich insbesondere in Abhängigkeit der technologischen Innovationen bewegt

8. ein «Bottom-up»-Phänomen, das von den Rauchenden ausgegangen ist und die Gesundheitsexperten überrascht hat.

Die wissenschaftlichen Daten zu den Auswirkungen der elektronischen Zigarette sind noch sehr fragmentarisch. Die Grundlagen für die Politik der öffentlichen Gesundheit und klinische Empfehlungen sind also unsicher und es wird heftig debattiert. Soll zum Beispiel Werbung für dieses Produkt erlaubt werden? Einige sind der Auffassung, dass es Jugendlichen den Einstieg in die Welt der Sucht erleichtern wird; andere hingegen glauben, dass es ebendiese Jugendlichen davon abhalten wird, mit den Tabakzigaretten anzufangen, und bei den erwachsenen Rauchenden - dazu beitragen wird, sich nicht mehr mit Verbrennungsprodukten des Tabaks zu vergiften. Aber viele Dampfer rauchen 
weiterhin Tabakzigaretten (wenn auch in geringerer Menge) und gefährden damit ihren Versuch, ihre Gesundheit zu erhalten!

Doch ist die Diskussion jetzt durch das Auftreten eines neuen Akteurs noch komplexer geworden: die Tabakindustrie. Diese kauft gerade Hersteller von Flüssigkeiten für elektronische Zigaretten auf, im Rahmen ihrer Promotion von weniger gefährlichen Produkten und ihrer sogenannten Politik der «Social Responsibility»! Mit welchen Konsequenzen? Einige postulieren, dass diese Industrie an der Beendigung des Marktes der Tabakzigaretten teilhaben, ein Akteur des Nikotinmarktes werden und die Bewerbung eines weniger schädlichen Erzeugnisses als Tabak fördern wird. Andere antizipieren, dass genau diese Strategie die technologische Innovation allmählich marginalisieren wird und so ermöglicht, den Tabakwarenmarkt zu erhalten. Wiederum andere fürchten, dass sie, während sie ihren tödlichen Tabakhandel weiter betreibt, auf diese Weise neue Marktsegmente erschliesst, vor allem bei den ehemaligen Raucherinnen und Rauchern, die so wieder Kunden werden könnten.

\section{Die Tabakindustrie besitzt keinerlei Glaub- würdigkeit, wenn sie behauptet, sozial und gesundheitlich verantwortlich zu sein.}

All diese Fragen sind von noch grösserer Aktualität, seitdem die Industrie andere Produkte auf den Markt gebracht hat, die als weniger schädlich verkauft werden, in denen der Tabak nicht mehr verbrannt, sondern nur erhitzt wird: die «Heat-not-burn»-Zigaretten! Viel Unsicherheit also ... Wenn man nicht weiss, was die Zukunft für uns bereithält, ist es hilfreich, einen Blick in die Vergangenheit zu werfen. Und da ist der Sachverhalt eindeutig: Die Tabakindustrie besitzt keinerlei Glaubwürdigkeit, wenn sie behauptet, sozial und gesundheitlich verantwortlich zu sein. Das Inverkehrbringen des Zigarettenfilters in den 1960er Jahren und der «leichten» Zigaretten in den 1970er Jahren, dann der Zusatz von Substanzen, um die "Suchtwirkung" (Ammoniak) und die Attraktivität (Kakao) ihrer Produkte zu erhöhen, verdeutlichen, wie sehr diese Indus- trie unverantwortlich ist. Und die Gegenwart bestätigt es: Die Tabakindustrie hat sich nicht geändert. Insbesondere ihre Art und Weise, die Jugendlichen über Werbung (vor allem durch das Duzen) in den «People»Seiten der Gratiszeitungen zu beeinflussen, und ihre juristischen Angriffe gegen die Länder, welche eine neue Tabakpräventions- und -kontrollpolitik implementieren (Australien, Uruguay).

Wie lässt sich also die Offenheit für das Dampfen mit der elektronischen Zigarette - ein zwar sicherlich viel weniger schädliches Produkt als Tabak - vereinbaren, ohne in die Fänge der Tabakindustrie zu geraten? Wie ein Medikament regulieren, zur Evaluation im Rahmen klinischer Studien zulassen, die Qualität unter Kontrolle bringen und die Herstellung durch diese unheilvolle Industrie verbieten? Wie ein Tabakerzeugnis regulieren, wie es die Schweiz vorbereitet? Aber wie streng soll reguliert werden? Für einige würde eine strikte Regulierung die Risiken der «Vereinnahmung» durch die Tabakindustrie verringern, während andere glauben, dass diese sich anpassen würde! Der Tabakindustrie Forderungen stellen, bevor die Vermarktung ihrer angeblich "weniger schädlichen" Erzeugnisse unterstützt wird? Diese Vorbedingungen wären demnach die Vermarktung der "neutralen» Einheitspackungen und das Ende jeglicher Werbung und der Rechtsstreite gegen verantwortliche Länder, die gegen den Tabakkonsum kämpfen? Eine letzte Möglichkeit könnte sein, abzuwarten, dass sich das Phänomen wie jede Modeerscheinung von selbst regelt, und sich (wieder) auf die oben geschilderten Massnahmen zu konzentrieren.

Wie auch immer, wir bleiben dran und beraten unsere rauchenden Patienten und Patientinnen bei ihrer Tabakentwöhnung weiter!

Bildnachweis

(C) Bega9000 | Dreamstime.com

Literatur

1 Le tabagisme. Martinet Y, Bohadana A. 2004. 3e éd Masson. Paris.

2 Cornuz J, Clair C. Prévention du tabagisme grâce à la cigarette électronique et aux nouveaux produits des cigarettiers: quand tout se complique! 